\title{
Primate thanatology and hominoid mortuary archeology
}

\author{
Paul Pettitt ${ }^{1}$ (D) James R. Anderson ${ }^{2}$
}

Received: 2 July 2019 / Accepted: 8 October 2019 / Published online: 23 October 2019

(c) The Author(s) 2019

\begin{abstract}
In recent years, a thanatology of primates has become a respectable research topic, and although still sparse, observations among several taxa have shown how complex responses to the dead can be. In human evolutionary archeology, re-analysis of old 'burial' sites is slowly revising our view on the development of specifically human responses to the dead. We propose here the means of integrating information from the two disciplines of primatology and archeology, in support of the field of primate thanatology. We propose a terminology and a shared set of research questions, from which we generate a number of observations that can be utilized in the field, in order to establish a working dialogue and foster greater collaboration across the two disciplines.
\end{abstract}

Keywords Thanatology $\cdot$ Funerary behavior $\cdot$ Hominoids $\cdot$ Evolution $\cdot$ Paleolithic $\cdot$ Death $\cdot$ Corpses

\section{Introduction}

In recent years, considerable advances have been made in our understanding of the behavior of an increasing number of nonhuman taxa towards dead conspecifics. In primatology, early accounts were largely anecdotal or second-hand with little verification, but researchers have come to realize the value of recording activities around and involving corpses, and as a result the field of primate thanatology is gaining both in momentum and credibility (Anderson 2011; Anderson et al. 2018; Gonçalves and Carvalho 2019). In evolutionary archaeology, while research is limited to the vagaries of archeological preservation, interest is finally turning away from old dichotomies that saw human groups that 'buried their dead' as 'cognitively modern' (whatever that is) and those that apparently did not as somehow less sophisticated, towards a more nuanced approach that recognizes that burial was relatively rare until the Late Pleistocene and that there are many ways to deal with corpses (Pettitt 2011, 2018). Long-term hypotheses for the development

Paul Pettitt

paul.pettitt@durham.ac.uk

1 Department of Archaeology, Durham University, Durham, UK

2 Department of Psychology, Graduate School of Letters, Kyoto University, Kyoto, Japan of mortuary behavior among the homininae are attracting attention and debate (Zilhão 2015); for the Neanderthals, re-evaluation and re-excavation of old sites has both rejected and supported previous material interpreted as burials, such as Roc de Marsal and la Chapelle-aux-Saints, respectively (Sandgathe et al. 2011; Rendu et al. 2014). Furthermore, new excavations in old sites pertinent to thanatology such as Shanidar Cave (Iraqi Kurdistan), where several Neanderthals were apparently buried, are beginning to provide a somewhat clearer picture (Pomeroy et al. 2017).

More widely, the accumulation of thanatological observations in nonhuman animals is revealing how some behaviors once thought to be 'sophisticated' and perhaps even exclusive to humans, are in fact widespread (McComb et al. 2006; Heinze and Walter 2010; de Waal 2013; Chouvenc et al. 2011; Renucci et al. 2011; López-Riquelme and FanjulMoles 2013; King 2013; Anderson 2016; de Kort et al. 2017; Bearzi et al. 2018; Gonçalves and Biro 2018; Gonçalves and Carvalho 2019). Examples include various methods of corpse disposal-described and systematically studied especially in eusocial insects and linked in particular to chemical cues - and post-mortem transport and care of dead infantsobserved especially in primates and cetaceans and studied from the perspectives of strong emotional bonds between individuals as well as those species' understanding of death. It has also been suggested that, as in early human societies, ways in which different populations of nonhuman species 
deal with dead conspecifics might show cultural variations (Biro et al. 2010), similar to many other cultural variations reported in primate populations (e.g., Whiten et al. 1999; McGrew 2003; Whiten 2011).

Recently, we attempted to define shared goals for an evolutionary thanatology that would encompass as inclusive a sample of animal taxa as possible, while also including modern, exclusively human sociological studies on topics such as the mortuary commemoration by humans of inorganic objects such as robots (Anderson et al. 2018). The breadth of scope of evolutionary thanatology is exemplified by a recently published themed issue of Philosophical Transactions of the Royal Society of London B, which included papers focusing on corpse management in eusocial insects, responses of corvids to dead conspecifics, responses to dead infants in cetaceans and primates, burials in early humans, children's developing understanding of death, human language and mental representations of death, suicide, whether the dead have moral standing, bereavement and grief, and recent cultural transformations in human funerary practices (see Anderson et al. 2018 and accompanying articles).

Here, we propose a predominantly primatological perspective on the development of methods for a more general and hypothesis-driven thanatology of our nearest evolutionary neighbors. Modern primatology and paleoanthropology (in this sense taken to be Paleolithic and Mesolithic archaeology, i.e., that of Pleistocene and early-mid Holocene hunter-gatherers), supplemented by evolutionary psychology are, we argue, the most appropriate disciplines from which one might develop testable hypotheses about the long-term evolution of anthropoid treatment of the dead. The two are to some extent complementary; by its very nature, primate thanatology deals with the face-to-face and the here-andnow, while the archaeology of early hunter-gatherers is limited to the inorganic materials that survive, and thus it tends to relate to place, rather than to demonstrable interactions between living and dead individuals. This is not to say that place and space should not be important to non-human primate thanatology, nor of course individual interactions in past human thanatology. On the contrary, we need methodologies to tease these out of developing data. As the number of primatological case studies increases it should be feasible to explore how space and landscapes are used among non-human primates, and new discoveries and analysis of Paleolithic and Mesolithic mortuary sites-particularly in the light of modern field and laboratory techniques, should allow a nuancing of how individual identities affected mortuary and funerary behaviors.

How might the spatially focused, complex mortuary activities (or mortuary complexes, to use the terminology of Duday 2009) observed among human societies over the last several millennia have evolved from our primate past? How complex, and how culturally variable are the mortuary behaviors observed among present-day primates? How much 'humanlike' behavior and cognition can be attributed to nonhuman primates in the mortuary realm, and how might these derive from earlier, mammalian or even pre-mammalian roots? Our goals for primate thanatology are to understand how widespread, homogeneous, or variable, behaviors are, and whether these derive from chemical, emotional, rational or cultural cores. How closely does the sociology of the dead map the sociology of the living? As the nature of social interaction between living individuals becomes more complex, is it inevitable that interaction with the dead does too? Or are certain factors such as the cause of death, age at death, or agent of death responsible for the ensuing activity? What, in particular, is so special about the simple inhumations in shallow graves that define the earliest burials?

\section{Terminology and semantics}

Fruitful cross-disciplinary collaboration and communication is best served by the common use of specific descriptors and definitions. What concepts are useful, and what language should we use? Below, we present four key behavioral categories that characterize discussions of the evolution of primate ways of dealing with the dead, in the hope that these terms might provide a useful framework for primatologists seeking to interpret their death-related observations within a wider thanatological perspective that includes modern and ancestral human mortuary activities. We make no attempt to review the available literature in depth; our intention is to provide a compromise heuristic framework for linking primatology and paleoanthropology; hopefully the project might expand to include other disciplines.

Avoidance reflects the deliberate avoidance of locations in which a death or deaths have occurred, or of specific places where predators (and therefore, death) are a palpable danger. In the wild, primates may temporarily avoid areas or abandon sleeping sites where conspecifics have recently been killed by predators (Altmann and Altmann 1970; Anderson 1984; Matsumoto-Oda 2015), but this might reflect fear of being attacked rather than a response to the other individual's death per se. In one well-documented case, however, captive chimpanzees temporarily avoided the location and in particular did not sleep where a group member had recently died from natural causes (Anderson et al. 2010). Archeological evidence of avoidance could take the form of localities where hominin remains are relatively abundant but in the context of a lack of other activities, such as has been argued for the 3.1-million-year-old AL-333 Australopithecus afarensis accumulation site at Hadar, Ethiopia (see Pettitt 2011 for discussion).

Corpse Interaction is defined as any expression of strong interest in, or interaction with, a corpse (defined as Morbidity in Pettitt 2011). This might include inspection 
of the corpse for signs of life or at least some kind of reaction; e.g., looking at, probing, or blowing into the corpse's eyes, touching or probing wounds or other body parts, and grooming. Other examples include displacing and transporting the corpse, and expressions of possible 'compassion,' such as care taking shown towards the corpse. Violent acts toward the corpse also come under corpse interaction, such as hitting, biting, or jumping on it, pulling out fur, nibbling parts of the corpse and other cannibalistic acts (for examples of various expressions of corpse interaction in primates see papers in this special issue, and Anderson et al. 2010; Biro et al. 2010; Cronin et al. 2011; Boesch 2012; Buhl et al. 2012; Stewart et al. 2012; Campbell et al. 2016; van Leeuwen et al. 2016; Yang et al. 2016; Pruetz et al. 2017; Porter et al. 2019).

Mortuary activity is a more general category that relates to any interaction with or actions stimulated by the corpse. This covers any observable behavior that can be reasonably and confidently associated with a corpse, including for example vocalizing, remaining in the vicinity of the corpse, repeatedly visiting it or the site after traces of the corpse have gone, deliberately modifying the landscape around the corpse, or interacting with others near to where the corpse is (landscape modification excepted, for examples see e.g., Teleki 1973; Boesch 2012; Pruetz et al. 2017).

Funerary activity is more specific, and defines any mortuary activity in which an element of active commemoration can be identified. Thus, funerary activity implies potentially higher-level cognitive processes than the other categories. In most cases, this involves simply using either the landscape (e.g., use of a particular location or topographical/landscape feature to dispose of the corpse) or tool use ("material culture", e.g., to dig a grave, or use of vegetation or stone to mark the location of a corpse), drawing attention to its presence and thus creating an association between that place and the dead. Undoubtedly, funerary activity has evolved particularly in the human lineage (Pettitt 2011), but one aim of the present article is to encourage primatologists to give greater consideration to the possibility of some incipient forms of funerary activities around the place where they witness death of a conspecific. In many or indeed most cases, there may be adequate explanations that need no reference to commemoration. For example, Boesch (2012) reported chimpanzees in the Tai Forest dropping vegetation onto corpses that they discovered unexpectedly, but parsimoniously interpreted this as a way of investigating the corpse from a safe distance, rather than as a specifically mortuary activity. Also, individuals revisiting the location where they previously witnessed death sometimes sniff the ground and vegetation (Pruetz et al. 2017), suggesting memory for the deceased and/or the death event. Such olfactory exploration might be simply to update their information about the deceased, or the possible presence of other individuals or species (e.g., scavengers, predators), although such cases might be better subsumed under the wider context of simple mortuary behavior.

\section{The wider ethological and anthropological context}

Until recently, the lack of detailed observations and video records of responses to their dead by primates, and the lack of detailed microsedimentological recording of archeological mortuary activity during the Paleolithic, meant that many potentially rich sources of information were not available. Modern archeological excavations benefit from highly technical forensic approaches to human death assemblages which provide considerable nuanced data on the corpse, its death, and its funerary context (Duday 2009), and postexcavation analyses have considerable analytical power to address osteoarcheological and paleopathological questions (e.g., Sandgathe et al. 2011; Sala et al. 2016; Pelletier et al. 2017; Pomeroy et al. 2017; Gómez-Olivencia et al. 2018; Sparacello et al. 2018, for recent Paleolithic examples). Molecular analysis such as isotope chemistry and ancient DNA can provide valuable biographic information on the deceased and their social context (Mittnik et al. 2016). In ideal circumstances, these combined analyses provide information akin to that extracted from both a forensic 'crime' scene, and a subsequent 'autopsy' as we might call them, even if the precise cause of death is often unknown. However, evidence for mortuary activity during the Paleolithic is scant (Pettitt 2011 and references therein), and restricted largely to burials that were recovered before modern standards of excavation, to stone tool cutmarks on human bones indicative of soft tissue removal (whether for cannibalism or more 'ritual' defleshing such as scalping) or fresh fractures of various forms for which 'natural' accidents can be discounted (see for example Sala et al. 2016), and to isolated human remains on occupation sites which may or may not derive from disturbed burials, curation of body parts (i.e., purposeful retention and carrying around of bones or teeth), or other forms of mortuary activity. Thus, most of the evidence deriving from our archeological 'crime scenes' is limited, even if one can deploy a suite of analyses on the human material that survives (Gowland and Knüsel 2006; Duday 2009).

In primatology, as of yet there is no archeology of mortuary activities, and maybe there never will be. Among living communities, however, the increasing number of deaths witnessed directly or discovered shortly after the event, often supplemented with detailed video records (e.g., Matsuzawa 1997; Anderson et al. 2010; Stewart et al. 2012; Cronin et al. 2011), means that more detailed qualitative and quantitative descriptions of the mortuary activities of monkeys and apes are becoming available for 
interpretation now, and for future reference. There are limitations, however, and in this context, we note the tendency of primate field workers, park staff, and caretakers of captive primate populations to remove a new corpse within a short period of time following the death, a practice that results in the loss of potentially useful information about subsequent primate mortuary activities. In the field, a death may rightly be looked upon as providing a source of materials for anatomical, pathological, or biochemical studies, etc., and indeed there exist recommended procedures for burial, excavation, and preparation of nonhuman primate skeletal remains (Garrod et al. 2015). Swift removal and disposal of corpses may also be justified in terms of prevention of the spread of disease (in both the field and captivity) (e.g., Porter et al. 2019), or in safari parks or zoos, to shield visitors from seeing dead animals, as the latter can give rise to negative reactions (e.g., Benbow 2004), and simply due to concerns about appropriate and ethical treatment of the dead. Such concerns are of course valid, but we call for greater consideration to be given to leaving corpses in situ whenever possible, in order to maximize information return about the responses of the living to the corpse, ideally until the group moves away and finally abandons it. The available literature strongly suggests that, except for predation and dead infant-carrying, corpses are usually abandoned within a few hours of death, so we hope that such recording need not be incompatible with the health and ethical concerns that currently determine conventional practices.

Clearly, decisions need to be made about the relative importance of obtaining more samples for morphological or biochemical research versus a better understanding of the taphonomy of primate death sites and any subsequent activities around them. Some aspects of modern forensic crime scenes could provide an appropriate model of how to proceed. One possible procedure might be to remove small samples of soft tissue, tooth and bone from a corpse in the field to be stored for DNA, isotope, and other analyses, leaving it largely intact and in the same posture and place. Such samples could be taken once the surviving members of the dead individual's group have left the corpse and moved away from the death site, as attempts to approach a corpse can elicit intense excitement and aggressive defense of it by members of the group which would hence affect observations (e.g., Campbell et al. 2016). Like others (e.g., Watson and Matsuzawa 2018), we recommend video recording of activities in the vicinity of a corpse when feasible. Also, remote video or camera traps can record mortuary activities even in the absence of direct observation, including reactions of other species in relation to the corpse. For example, over a 25-day period, Huang et al. (2014) captured over 4000 photographs of three mammalian and one avian species scavenging on a Golden snub-nosed monkey carcass in Sichuan, China. No member of the dead monkey's social group returned to the area, but whether this reflects active avoidance is unclear, as the preserved carcass was only returned to the site after a 3-week delay.

\section{Research questions for primate thanatology}

With regard to extinct and extant primates including humans, mortuary activity can range from brief vocal and somatic expressions of emotional reactions to death and accompanying social displays, to the repeated use of particular places for the ritual disposal of the dead and the use of such to reflect age, gender, status, and other social differences between individuals that they presumably held in life (Binford 1971). A growing complexity of mortuary activity over time may of course reflect—or at least broadly track — cognitive evolution, although this needs to be demonstrated rather than simply assumed in progressivist evolutionary narratives. If group size and social complexity can to an extent be correlated with brain size over the course of primate evolution (Dunbar 2003), does it necessarily follow that as group complexity grows, so too does the complexity of mortuary activity, as hypothesized by Pettitt (2018)? Recent observations on primates and indeed other taxa suggest that mortuary activity can be relatively complex, although without necessarily implying any cognitively sophisticated underpinnings such as 'symbolic' capacities or anything that makes it specifically funerary in our sense (Anderson et al. 2010, 2018; Gonçalves and Carvalho 2019). Primate thanatology should, we suggest, focus on building up a volume of observations that can be used to test specific models about what factors promote relatively complex mortuary activities, and in particular when and why places in the landscape begin to be associated with the dead.

By focusing on our nearest living evolutionary neighbors, we can generate a core of mortuary behaviors that we might expect to have been expressed, however variably, among Miocene, Pliocene, and Pleistocene hominoids and hominins. At present, most information is available for chimpanzees, with accounts of reactions to dead conspecifics in captive, semi free-ranging, and wild settings (Anderson 2018). The most widely documented suite of responses concerns the maternal transport and caretaking of dead infants, a behavior which is not restricted to great apes (Sugiyama et al. 2009; Watson and Matsuzawa 2018; Das et al. 2018; Gonçalves and Carvalho 2019). The fact that it has been reported in multiple species and in different chimpanzee populations argues against the idea (e.g., Biro et al. 2010) that dead infant-carrying might be culturally determined, although it is possible that specific aspects of handling dead infants, or even the motivation to do it, might be socially influenced, i.e., vary between individuals, groups, or taxa; this remains to be seen. Does the apparent strength of bond between a 
mother and her offspring also explain the Middle Paleolithic burial of a mother with her fetus/neonate at Ostuni, Italy (Vacca and Coppola 1993), the Mid Upper Paleolithic burial of three infants at Krems-Wachtberg, Austria (Einwögerer et al. 2006, 2008), and an elderly female clasping in her arms a chondritic dwarf in the Late Upper Paleolithic levels of the Romito rockshelter, Italy (Frayer et al. 1987, 1988)? What social relationships might underpin the Mid Upper Paleolithic triple adult burials of Barma Grande in Italy and Dolní Věstonice in the Czech Republic (Formicola 1988; Formicola et al. 2001)? With Paleolithic burials-whether Neanderthals or Homo sapiens, are we dealing with behavior that is determined by blood relationships, or by relationships of hierarchical rank [or social status?] and competition?

More generally, questions about intra- and inter-group variability, and possible cultural influences on mortuary activity among the living primates cannot yet be answered due to insufficient observations. Going beyond dead group members other than infants, chimpanzees have variously been reported to inspect dead bodies visually and olfactorily, gently touch, caress, or hold the hand of, a deceased group member, groom the body, wave away flies and remove dirt or debris, hit, pull, jump on and drag the body, inspect and manipulate it via a stick, and in some cases to drop branches on it from above; various degrees of cannibalism have also been reported (see e.g., Teleki 1973; Anderson et al. 2010; Boesch 2012; Stewart et al. 2012; Pruetz et al. 2017). Below, we present four major questions that we believe to be both testable and pertinent for primate thanatology. The list is neither exhaustive nor in any particular order; we invite readers to prioritize the questions according to their own research circumstances, and to modify the questions as appropriate and add new ones. In Table 1, we attempt to formulate more specific questions that could guide field observations in ways that should allow us to address these major questions.

1. Does the complexity of mortuary activity among primates increase with increasing group size or complexity (e.g., including increasing evidence of theory of mind, long-term social relationships based on kinship and friendship, exchange of social goods or services), and might this provide a mechanism or reason for mortuary evolution among the hominins? The Paleolithic record certainly indicates that mortuary behavior is more evident and more variable from the Late Middle Pleistocene and early Upper Pleistocene, among Neanderthal and Homo sapiens groups with encephalization quotients demonstrably higher than their Middle Pleistocene predecessors. But does this development pertain only to these groups, or is it a more general rule?

2. Do 'bad' deaths, those that are sudden or unpredicted, occasion more interest and activity than those that seem more 'expected'? This may pertain in particu- lar to infants or adults in their prime. Pettitt (2018) hypothesized that this is the case for chimpanzees; in six recorded examples more individuals engaged in corpse-related behaviors such as corpse interaction and social displays, and for longer periods of time, in situations where deaths resulted from tree falls or predator ambush, i.e., were unexpected and traumatic. But the observations are few and incomplete: what percentage of the total group was distracted from other activities by these deaths; do responses across populations vary in ways that suggest different cultures? Mid Upper Paleolithic burials are often of individuals with observable pathologies and/or violent or otherwise sudden deaths (Trinkaus et al. 2001; Formicola 2007). An ethnographic survey of diverse hunter-gatherer groups showed that they tend to believe that death is natural (i.e., inevitably comes to everyone) except in the case of the very young and adults in their prime (Binford 2004). The universality component of the death concept (i.e., the acknowledgement that everyone dies) is an open question for primatology, especially in the great apes, given their capacities for self-awareness (Anderson and Gallup 2011, 2015).

3. How widespread is the concern to cover or otherwise hide a corpse, and does this relate to the processes of necroclaustralization (covering) and necrophoresis (removal) observed among various insect taxa? The relative paucity of burials before the rise of semi-sedentary, complex hunter-gatherers of the Late Pleistocene suggests that simple abandonment or necrophoresis may have pertained for much of the course of human evolution. A major watershed would therefore be the rise of the practice of funerary caching - the deliberate deposition of corpses in natural places such as fissures and caves-among Homo heidelbergensis groups from the mid Middle Pleistocene ( 500,000 BP), and Homo neanderthalensis and Homo sapiens in the late Middle Pleistocene and Upper Pleistocene 115,000 BP onwards (Pettitt 2018). This suggests that by this time hominins had extended the process of corpse removal from campsites to their deliberate deposition at specific places. Thus, can we recognize an evolutionary development from abandonment to necrophoresis to necroclaustralization, ultimately resulting in specific places for the disposal of the dead? With the possible exception of dropping vegetation on "unexplained" conspecific corpses by chimpanzees (Boesch 2012), there is as yet little evidence of corpse caching in nonhuman primates. Nor has moving or attempting to move corpses to specific locations been recorded, but we believe that it would be worthwhile to pay greater attention to recording distances over which corpses are sometimes dragged, and the precise types of location where they 


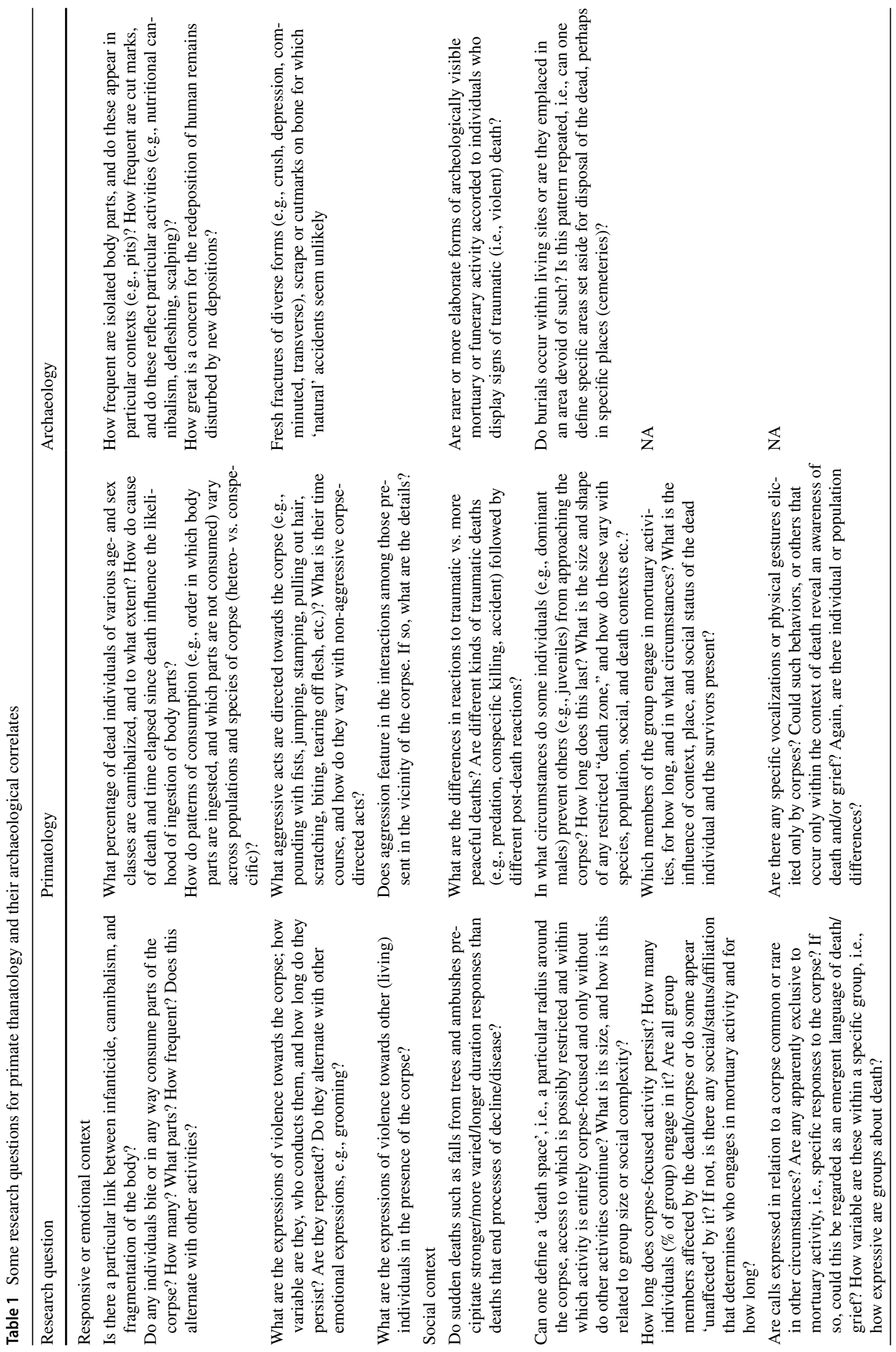




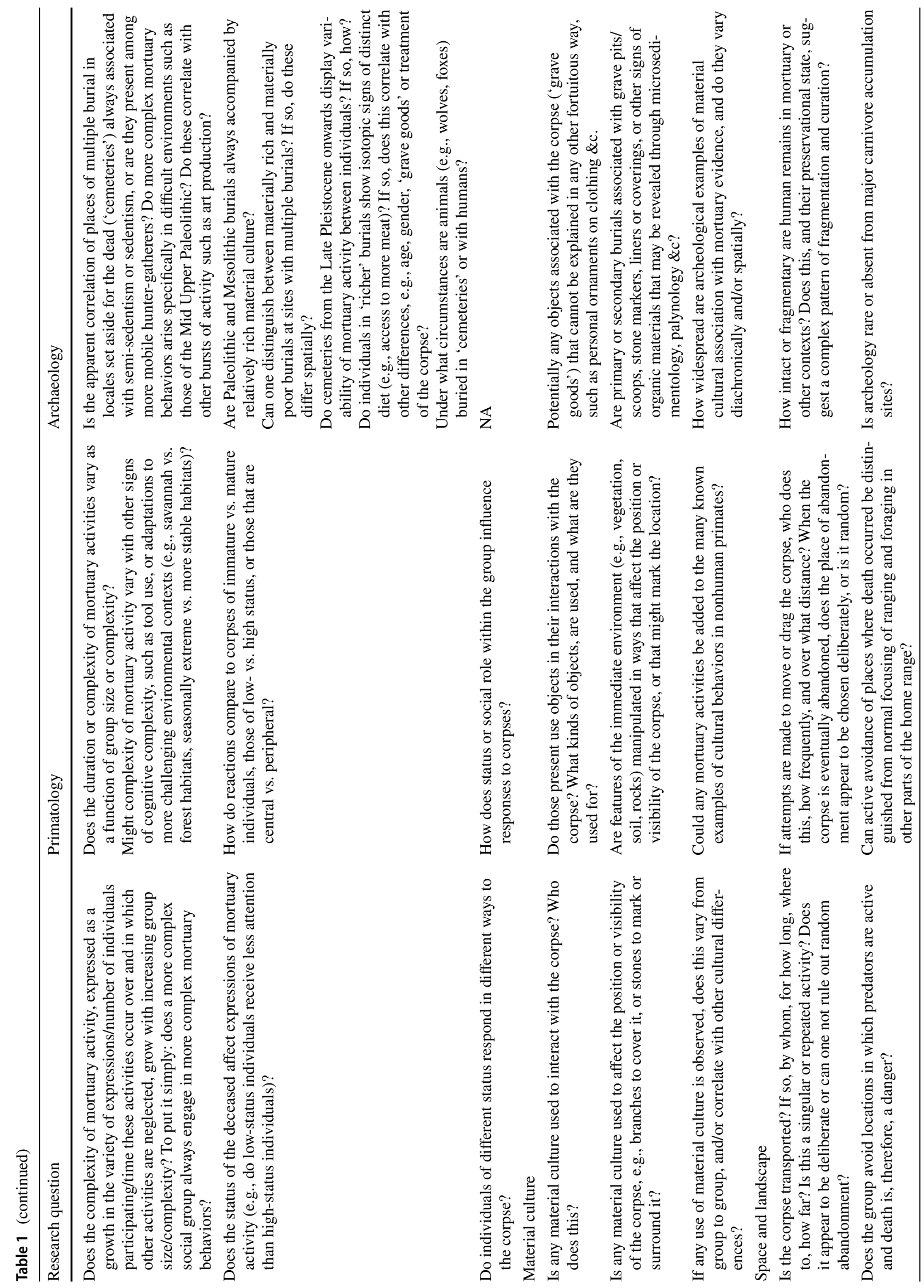


are eventually abandoned. Other pertinent questions include, for example, whether larger primate groups take longer to fully abandon a corpse. Might attempts to move the corpse be related to the size and social status of the individual when alive, and aspects of the social group such as age-to-sex ratio, absolute size etc.?

4. Is there a general rule that the stronger the social attachment between individuals, the stronger or more protracted the process of detachment, (sensu Gamble 1999); i.e., expressions of corpse interaction, grief, mortuary, and funerary activity? This question in relation to nonhuman primates has been addressed with particular references to mothers' responses to their dead infants (Sugiyama et al., 2009; Anderson 2017; Watson and Matsuzawa 2018; Das et al. 2018; Gonçalves and Carvalho 2019), but recent reports have highlighted notable behaviors by individuals towards the corpses of non-kin individuals with whom they shared strong social bonds before the death (Anderson et al. 2010; Bezerra et al. 2014; van Leeuwen et al. 2016; Yang et al. 2016). Closer analyses of post-death behaviors in relation to pre-death social relationships in extant primates appears fundamental for the development of primate thanatology.

To clarify how to approach these major questions, we divide primate thanatology into several heuristic areas, namely: responsive (or emotional) context, social context, material culture, space, and landscape. We do not consider our research questions or heuristic areas to be in any way exhaustive, and we are aware of the speculative nature of some of them; but they can hopefully serve as a way of orienting primatologists towards the kinds of observations that would help address a wide range of hypotheses about the long-term evolution of primate-particularly great apemortuary activity. We similarly want to orientate archeologists to a meaningful discourse with primatologists. Such a discourse can address the issue of what constitutes the major changes from an ape-like to a human-like mortuary behavior, one that extends from the 'face to face' to place. What factors determine how the temporal or spatial scale of such behaviors increases within and between groups and over the course of hominoid evolution? Is mortuary activity usually more focused on the dead (e.g., their status in life, ties to the living, or cause of death) or on the living (e.g., how individuals renegotiate their position in the group social structure after a death); are there any vocalizations, postures, or behavioral displays (e.g., unusual calls, copulation, aggression or other behaviors) that specifically address the corpse, the living, or both?

Table 1 presents some specific research questions and observation desiderata for primatology and archaeology, organized according to the main heuristic contexts outlined above. Rather than being complete or containing questions 
to be equally addressed by both disciplines, we see this list as a guide to action, providing food for thought in the field, and a proposal to share objectives using a unified terminology. Existing reports pertinent to some of questions for primatology are cited in Anderson (2017, 2018), Gonçalves and Biro (2018), Gonçalves and Carvalho (2019), and Watson and Matsuzawa (2018); for archeology see Pettitt (2011, 2018) and Zilhão (2015).

\section{Conclusions}

Our proposals here are a first, and therefore a modest attempt to begin developing a shared terminology and methodology between primatologists and archeologists. We argue that archeologists and primatologists are particularly well suited to undertaking this together. The extent to which observations on the living in the present world can be meaningfully linked to analyses of excavated materials pertaining to the long-dead is of course questionable, and will leave much to be desired. But we believe that there is enough scope for at least a cautious joint project on the long-term development and diversity of mortuary behaviors. The project is relevant to primatologists and other animal behavior researchers, psychologists, anthropologists, and archeologists, among others. The field is new, and observations still scant. For this reason, we believe it important to develop an observational methodology now, with which further observations can be documented in ways as to maximize their utility. We may be sure that a number of our proposed questions will remain unanswered or unanswerable; that our methodologies will remain in need of further refinement and correction; and that there will be alternative perspectives on primate thanatology. But we strongly feel that it is a project worth pursuing.

Acknowledgements JRA was financially supported by JSPS KAKENHI Grant No. 18K18693. The authors thank two anonymous reviewers for their helpful comments.

Open Access This article is distributed under the terms of the Creative Commons Attribution 4.0 International License (http://creativeco mmons.org/licenses/by/4.0/), which permits unrestricted use, distribution, and reproduction in any medium, provided you give appropriate credit to the original author(s) and the source, provide a link to the Creative Commons license, and indicate if changes were made.

\section{References}

Altmann SA, Altmann J (1970) Baboon ecology: African field research. University of Chicago Press, Chicago

Anderson JR (1984) Ethology and ecology of sleep in monkeys and apes. Adv Stud Behav 14:165-229

Anderson JR (2011) A primatological perspective on death. Am J Primatol 73:410-414
Anderson JR (2016) Comparative thanatology. Curr Biol 26:R553-R556

Anderson JR (2017) Comparative evolutionary thanatology of grief, with special reference to nonhuman primates. Japan Rev Cult Anthropol 18:173-189

Anderson JR (2018) Chimpanzees and death. Phil Trans R Soc B 373:20170257. https://doi.org/10.1098/rstb.2017.0257

Anderson JR, Gallup GG Jr (2011) Which primates recognize themselves in mirrors? PLoS Biol 9(3):e1001023. https://doi. org/10.1371/journal.pbio.1001024

Anderson JR, Gallup GG Jr (2015) Mirror self-recognition: a review and critique of attempts to promote and engineer self-recognition in primates. Primates 56:317-326

Anderson JR, Gillies, Lock LC (2010) Pan thanatology. Curr Biol 20:R349-R351

Anderson JR, Biro D, Pettitt P (2018) Evolutionary thanatology. Phil Trans R Soc B 373:20170262. https://doi.org/10.1098/ rstb.2017.0262

Bearzi G, Kerem D, Furey NB, Pitman RL, Rendell L, Reeves RR (2018) Whale and dolphin responses to dead conspecifics. Zoology $128: 1-15$

Benbow SMP (2004) Death and dying at the zoo. J Pop Cult 37:379-398

Bezerra BM, Keasey MP, Schiel N, da Silva Souto A (2014) Responses toward a dying adult group member in a wild New World monkey. Primates 55:185-188

Binford L (1971) Mortuary practices; their study and potential. In: Brown JA (ed) Approaches to the social dimensions of mortuary practices. Society for American Archaeology Memoir 25, pp 208-243

Binford L (2004) Beliefs about death, behaviour and mortuary practices among hunter-gatherers; a search for causal structure? In: Cherry J, Scarre C, Shennan S (eds) Explaining social change. Studies in honour of Colin Renfrew. Cambridge University Press, Cambridge, pp 1-16

Biro B, Humle T, Koops K, Sousa C, Hayashi M, Matsuzawa T (2010) Chimpanzee mothers at Bossou, Guinea carry the mummified remains of their dead infants. Curr Biol 20:R351-R352

Boesch C (2012) Wild cultures: a comparison between chimpanzee and human cultures. Cambridge University Press, New York

Buhl JS, Aure B, Ruiz-Lambides A, Gonzalez-Martinez J, Platt ML, Brent LJN (2012) Response of rhesus macaques (Macaca mulatta) to the body of a group member that died from a fatal attack. Int J Primatrol 33:860-871

Campbell LAD, Tkaczynski PJ, Mouna M, Qarro M, Waterman J, Majolo B (2016) Behavioral responses to injury and death in wild Barbary macaques (Macaca sylvanus). Primates 57:309-315

Chouvenc T, Robert A, Sémon E, Bordereau C (2011) Burial behaviour by dealates of the termite Pseudacanthotermes spiniger (Termitidae, Macrotermitinae) induced by chemical signals from termite corpses. Insectes Soc 59:119-125

Cronin KA, van Leeuwen EJC, Mulenga IC, Bodamer MD (2011) Behavioral response of a chimpanzee mother toward her dead infant. Am J Primatol 73:415-421

Das S, Erinjery JJ, Desai N, Mohan K, Kumara HN, Singh M (2018) Deceased-infant carrying in nonhuman anthropoids: insights from systematic analysis and case studies of bonnet macaques (Macaca radiata) and lion-tailed macaques (Macaca silenus). J Comp Psychol. https://doi.org/10.1037/com0000140

De Kort D, Althrichter M, Cortez S, Camino M (2017) Collared peccary (Pecarry tajacu) behavioral reactions toward a dead member of the herd. Ethology 124:131-134

De Waal F (2013) The Bonobo and the Atheist. Norton, New York

Duday H (2009) The archaeology of the dead: lectures in archaeothanatology. OxBow, Oxford 
Dunbar R (2003) The social brain: mind, language and society in evolutionary perspective. Annu Rev Anthropol 32:163-181

Einwögerer T, Friesinger H, Händel M, Neugebauer-Maresch C, Simon U, Teschler-Nicola M (2006) Upper Palaeolithic infant burials. Nature 444:285

Einwögerer T, Händel M, Neugebauer-Maresch C, Simon U, TeschlerNicola M (2008) The Gravettian infant burials from KremsWachtberg, Austria. In: Bacvarov K (ed) Babies reborn: infant/ child burials in pre- and protohistory. BAR International series, Oxford, pp 15-19

Formicola V (1988) The triplex burial of Barma Grande (Grimaldi, Italy). Homo 39:130-143

Formicola V (2007) From the Sungir children to the Romito dwarf. Aspects of the Upper Palaeolithic funerary landscape. Curr Anthropol 48:446-453

Formicola V, Pontrandolfi A, Svoboda J (2001) The Upper Palaeolithic triple burial of Dolní Věstonice: pathology and funerary behavior. Am J Phys Anthropol 115:372-379

Frayer DW, Horton WA, Macchiarelli R, Mussi M (1987) Dwarfism in an adolescent from the Italian Late Upper Palaeolithic. Nature 330:60-62

Frayer DW, Macchiarelli R, Mussi M (1988) A case of chondrodystrophic dwarfism in the Italian Late Upper Palaeolithic. Am J Phys Anthropol 75:549-565

Gamble C (1999) The Palaeolithic societies of Europe. Cambridge University Press, Cambridge

Garrod B, Roberts AM, Duhig C, Cox D, McGrew W (2015) Burial, excavation, and preparation of primate skeletal material for morphological study. Primates 56:311-316

Gómez-Olivencia A, Quam R, Sala N, Bardey M, Ohman J, Balzeau A (2018) La Ferrassie 1: new perspectives on a "classic" Neandertal. J Hum Evol 117:13-32

Gonçalves A, Biro D (2018) Comparative thanatology, an integrative approach: exploring sensory/cognitive aspects of death recognition in vertebrates and invertebrates. Phil Trans R Soc B 373:2070263

Gonçalves A, Carvalho S (2019) Death among primates: a critical review of non-human primate interactions towards their dead and dying. Biol Rev. https://doi.org/10.1111/brv.12512

Gowland R, Knüsel C (2006) Social archaeology of funerary remains. OxBow, Oxford

Heinze J, Walter B (2010) Moribund ants leave their nests to die in social isolation. Curr Biol 20:249-252

Huang Z-P, Qi X-G, Garber PA, Li B-G, Jin T, Guo S-T, Li S, Li B-G (2014) The use of camera traps to identify the set of scavengers preying on the carcass of a golden snub-nosed monkey (Rhinopithecus roxellana). PLoS One 9(2):e87318. https://doi. org/10.1371/journal.pone.0087318

"Jokro: the death of an infant chimpanzee." Video, Primate Research Institute

King B (2013) How animals grieve. Chicago University Press, Chicago

López-Riquelme GO, Fanjul-Moles ML (2013) The funeral ways of social insects. Social strategies for corpse disposal. Trends Entomol 9:71-129

Matsumoto-Oda A (2015) How surviving baboons behaved after leopard predation: a case report. Anthropol Sci 123:13-17

Matsuzawa T (1997) 2003) The death of an infant chimpanzee at Bossou, Guinea. Pan Africa News 4:4-6

McComb K, Baker L, Moss C (2006) African elephants show high levels of interest in the skulls and ivory of their own species. Biol Lett 2:26-28

McGrew WC (2003) Culture in nonhuman primates? Annu Rev Anthropol 27:301-328

Mittnik A, Wang C-C, Svoboda J, Krause J (2016) A molecular approach to the sexing of the triple burial at the Upper palaeolithic site of Dolní Věstonice. PLoS One 11(10):e163019
Pelletier M, Royer A, Holliday TW, Discamps E, Madelaine S, Maureille B (2017) Rabbits in the grave! Consequences of bioturbation on the Neanderthal 'burial' at Le Regourdou (Montignac-surVézère, Dordogne). J Hum Evol 110:1-17

Pettitt P (2011) The Palaeolithic origins of human burial. Routledge, London

Pettitt P (2018) Hominin evolutionary thanatology from the mortuary to funerary realm. The palaeoanthropological bridge between chemistry and culture. Phil Trans R Soc B. https://doi. org/10.1098/rstb.2018.0212

Pomeroy E, Lahr M, Crivellaro F, Farr L, Reynolds T, Hunt C, Barker G (2017) Newly discovered Neanderthal remains from Shanidar Cave, Iraqi Kurdistan, and their attribution to Shanidar 5. J Hum Evol 111:102-118

Porter A, Eckardt W, Vecellio V, Guschanski K, Niehoff PP, NgoboboAs-Ibungu U, Nishuli Pekeyake R, Stoinski T, Caillaud D (2019) Behavioral responses around conspecific corpses in adult eastern gorillas (Gorilla beringei spp.). PeerJ 7:e6655. https://doi. org/10.7717/peerj.6655

Pruetz JD, Ontl KB, Cleaveland E, Lindshield S, Marshack J, Wessling EG (2017) Intragroup lethal aggression in West African chimpanzees (Pan troglodytes verus): inferred killing of a former alpha male at Fongoli, Senegal. Int J Primatol 38:31-57

Rendu W, Beauval C, Crevecoeur I, Bayle P, Balzeau A, Bismuth T, Bourguignon L, Delfour G, Faivre J-P, Lacrampe-Cuyaubère F, Tavormina C, Todisco D, Turq A, Maureille B (2014) Evidence supporting an intentional Neanderthal burial at La Chapelle-auxSaints. Proc Natl Acad Sci USA 111:81-86

Renucci M, Tirard A, Provost E (2011) Complex undertaking behaviour in Temnothorax lichtensteini ant colonies: from corpse-burying behaviour to necrophoric behavior. Insectes Soc 58:9-16

Sala N, Pantoja-Pérez A, Arsuaga JL, Pablos A, Martínez I (2016) The Sima de los Huesos Crania: analysis of the cranial breakage patterns. J Archaeol Sci 72:25-43

Sandgathe D, Dibble H, Goldberg P, McPherron S (2011) The Roc de Marsal Neanderthal child: a reassessment of its status as a deliberate burial. J Hum Evol 61:243-253

Sparacello V, Rossi S, Pettitt P, Roberts C, Riel-Salvatore J, Formicola V (2018) New insights on Epigravettian funerary behavior at Arene Candide Cave (Liguria, Italy). J Anthropol Sci 96:1-24

Stewart FA, Piel AK, O'Malley RC (2012) Responses of chimpanzees to a recently dead community member at Gombe National Park, Tanzania. Am J Primatol 74:1-7

Sugiyama Y, Kurita H, Matsui T, Kimoto S, Shimomura T (2009) Carrying of dead infants by Japanese macaque (Macaca fuscata) mothers. Anthropol Sci 117:113-119

Teleki G (1973) Group response to the accidental death of a chimpanzee in Gombe National Park, Tanzania. Folia Primatol 20:81-94

Trinkaus E, Formicola V, Svoboda J, Hillson SW, Holliday TW (2001) Dolní Věstonice 15: pathology and persistence in the Pavlovian. J Archaeol Sci 28:1291-1308

Vacca E, Coppola D (1993) The Upper Palaeolithic burials at the cave of Santa Maria di Agnano (Ostuni, Brindisi): preliminary report. Riv Antropol 71:275-284

van Leeuwen EJC, Mulenga IC, Bodamer MD, Cronin KA (2016) Chimpanzees' responses to the dead body of a 9-year-old group member. Am J Primatol 78:914-922

Watson CFI, Matsuzawa T (2018) Behaviour of nonhuman primate mothers toward their dead infants: uncovering mechanisms. Phil Trans R Soc B 373:20170261. https://doi.org/10.1098/ rstb.2017.0261

Whiten A (2011) The scope of culture in chimpanzees, humans and ancestral apes. Phil Trans R Soc B 366:997-1007

Whiten A, Goodall J, McGrew WC, Nishida T, Reynolds V, Sugiyama Y, Tutin CEG, Wrangham RW, Boesch C (1999) Cultures in chimpanzees. Nature 399:682-685 
Yang B, Anderson JR, Li B-G (2016) Tending a dying adults in a wild multi-level primate society. Curr Biol 26:R403-R404

Zilhão J (2015) Lower and Middle Palaeolithic mortuary behaviours and the origins of ritual burial. In: Renfrew C, Boyd MJ, Morley I (eds) Death rituals, social order and the archaeology of immortality in the ancient world. Cambridge University Press, Cambridge, pp 27-44
Publisher's Note Springer Nature remains neutral with regard to jurisdictional claims in published maps and institutional affiliations. 